\title{
Increased sucrose levels mediate selective mRNA translation in Arabidopsis
}

\author{
Magdalena Gamm¹, Alessia Peviani², Anne Honsel ${ }^{3}$, Berend Snel ${ }^{2}$, Sjef Smeekens ${ }^{1}$ and Johannes Hanson ${ }^{1,3^{*}}$
}

\begin{abstract}
Background: Protein synthesis is a highly energy demanding process and is regulated according to cellular energy levels. Light and sugar availability affect mRNA translation in plant cells but the specific roles of these factors remain unclear. In this study, sucrose was applied to Arabidopsis seedlings kept in the light or in the dark, in order to distinguish sucrose and light effects on transcription and translation. These were studied using microarray analysis of steady-state mRNA and mRNA bound to translating ribosomes.

Results: Steady-state mRNA levels were affected differently by sucrose in the light and in the dark but general translation increased to a similar extent in both conditions. For a majority of the transcripts changes of the transcript levels were followed by changes in polysomal mRNA levels. However, for 243 mRNAs, a change in polysomal occupancy (defined as polysomal levels related to steady-state levels of the mRNA) was observed after sucrose treatment in the light, but not in the dark condition. Many of these mRNAs are annotated as encoding ribosomal proteins, supporting specific translational regulation of this group of transcripts. Unexpectedly, the numbers of ribosomes bound to each mRNA decreased for mRNAs with increased polysomal occupancy.
\end{abstract}

Conclusions: Our results suggest that sucrose regulate translation of these 243 mRNAs specifically in the light, through a novel regulatory mechanism. Our data shows that increased polysomal occupancy is not necessarily leading to more ribosomes per transcript, suggesting a mechanism of translational induction not solely dependent on increased translation initiation rates.

Keywords: Arabidopsis, Protein synthesis, Sugar signaling, Translational regulation

\section{Background}

Plant growth and development depend on energy provided by carbohydrates and the coordination of its storage and mobilization. Energy-consuming processes must be controlled to coordinate growth with energy availability in an ever-changing environment. One of the most energydemanding cellular processes is protein synthesis: energy has to be provided for amino acid and tRNA synthesis, peptide bond formation, and the biogenesis of the translational machinery [1]. In Arabidopsis rosettes, 10\% of the proteins were estimated to be ribosomal proteins, but these numbers are likely higher in rapidly growing tissues [2]. In addition, a large number of non-ribosomal proteins

\footnotetext{
* Correspondence: johannes.hanson@umu.se

${ }^{1}$ Molecular Plant Physiology, Institute of Environmental Biology, Utrecht

University, Utrecht, The Netherlands

${ }^{3}$ Umeå Plant Science Centre, Department of Plant Physiology, Umeå

University, SE-90187 Umeå, Sweden

Full list of author information is available at the end of the article
}

are needed for initiation, elongation, termination, and ribosome recycling during mRNA translation [3]. Translation is considered to be regulated at initiation [4], while elongation and termination rates are proposed to be less affected in most conditions [5]. Initiation rates control the loading of the mRNA into polysomes, affecting translational efficiency [6,7]. How specific mRNAs are selected for translation is poorly understood. A number of mRNA features have been proposed to be involved in translational regulation, including 5'UTR length and nucleotide sequence composition, secondary structure, the presence of uORFs, as well as different cis-acting motifs within the mRNA sequence $[8,9]$.

Several studies address the adaptation of translational efficiency to changes in environmental conditions like mild dehydration [8], hypoxia $[9,10]$, salt and high temperature $[11,12]$. Stress conditions generally affect translation by decreasing both polysomal occupancy (fraction of an mRNA present in polysomes) and ribosome density (number of 
ribosomes per mRNA). Interestingly, some mRNAs escape this general stress mediated reduction of translation and maintain or increase polysomal occupancy, ensuring the production of proteins necessary for adaptation. Such translational control is essential for the plant's response to stress and adds another layer to the regulation of gene expression [13,14]. Translation of other mRNAs is strongly repressed under stress conditions, while their steady-state transcript levels do not change [15]. Recently, some of these mRNAs were found to associate with the UBP1 RNA-binding protein during hypoxia [16]. UBP1 might be involved in sequestering mRNAs in cytoplasmic granules for the duration of the stress and their release for translation during recovery, thus providing a mechanism of translational regulation [16]. Interestingly, the formation of these UBP1-granules might be connected to ATP availability [16], suggesting a link between energy availability and translation. Energy availability has been implicated to affect protein synthesis at several levels [1,17-19].

Increased sucrose availability correlates with increased association of mRNAs to polysomes during daytime, whereas during the night protein synthesis is adapted to limit energy consumption $[1,18]$. Sucrose starvation of cultured Arabidopsis cells represses translation of most mRNAs, generally independent of changes in steadystate mRNA levels [17]. Similarly, low sugar status induced by unexpected dark treatment of Arabidopsis seedlings leads to a reduction of translation, with mRNAs being sequestered and re-initiated rapidly after re-illumination [19]. Interestingly, many of the mRNAs affected by varying sugar levels encode ribosomal proteins.

Ribosomal protein genes are among the main targets of translational control in many experiments, for example after growth stimulation of germinated maize embryos [20]. Recently, mRNAs encoding ribosomal proteins were proposed to form a 'regulon' of coordinated translational regulation [14], likely dependent on the initiation factor eIF3h and the ribosomal protein RPL24B [21]. In Arabidopsis thaliana, ribosomal proteins are encoded by more than 240 genes [22,23] of which most are translated to proteins as judged by proteomic experiments [23-25]. Generally, only a single protein of each of the 81 protein families is present in the functional ribosome leading to a great number of possible combinations [26]. A role of the resulting ribosomal heterogeneity is yet to be identified, but mutants lacking specific paralogs of ribosomal proteins often display severe and distinguishable phenotypes [27,28]. Possibly, the differential composition of ribosomes in response to changes in growth conditions contributes to the selective translation of mRNA subsets $[29,30]$. Interestingly, sucrose treatment was shown to significantly change ribosomal protein composition [31]. The finding that sucrose concentrations correlate with general translational activity [1] and affect ribosomal protein composition suggest a function for sucrose in translational control and, possibly, mRNA selection. A further source of ribosome heterogeneity is post-translational modification of ribosomal proteins. Recently, a number of plant ribosomal proteins and initiation factors (eIFs) were shown to be phosphorylated in response to photosynthetic activity [32,33]. Interestingly, phosphorylation of eIF3C, eIF5A2, and eIF5A3 was found to be dependent on light, but independent of net photosynthesis [33], indicating that light might play a role in translational control independent of the energy aspect. Light was shown to induce translational activity in etiolated seedlings [34], during the diurnal cycle [18], or after an unexpected dark treatment [19]. However, the specific roles of light and sugars in translational control have not been studied so far. Furthermore, while the general effects of energy metabolism on protein synthesis have been described, the effect of sugars on translation of specific mRNAs has not been studied in detail. Until now, most of the studies on translational regulation address stress mediated reduction of translation, and little information is available on the regulation of increase in translation. It is unknown whether translational inhibition and stimulation use the same or different regulatory mechanisms.

We hypothesize that specific genes are translationally stimulated in response to sugar levels. In this study, we analyze the effect of sucrose on seedlings under light or dark conditions in order to uncouple light and sugar effects and to identify mRNAs differentially translated under these conditions. We confirm the general induction of translation in response to increased sucrose concentration in both light and dark treatments. However, polysomal occupancy of a number of genes was found to increase specifically after sucrose treatment in the light. Most of these sucrose responsive mRNAs are poorly translated under the control (no sucrose) conditions and do not change in steady-state abundance after sucrose treatment. Ribosomal protein mRNAs are among those found to be controlled by sucrose at the translational level. Interestingly, the increase in polysomal occupancy is not accompanied by an increase in ribosome density, indicating the involvement of a novel mechanism in translational stimulation in response to sucrose.

\section{Results}

\section{Metabolic effects of the sugar treatments in different conditions}

The biological material used and the experiments performed in this study are summarized in Figure 1. Sucrose treatments were applied to Arabidopsis seedlings both in the dark and in the light in order to uncouple the effects of sucrose and light on translation. To adjust for osmotic changes of the media control samples were treated with equimolar concentrations of sorbitol. Metabolite changes induced in the seedlings under the different conditions 


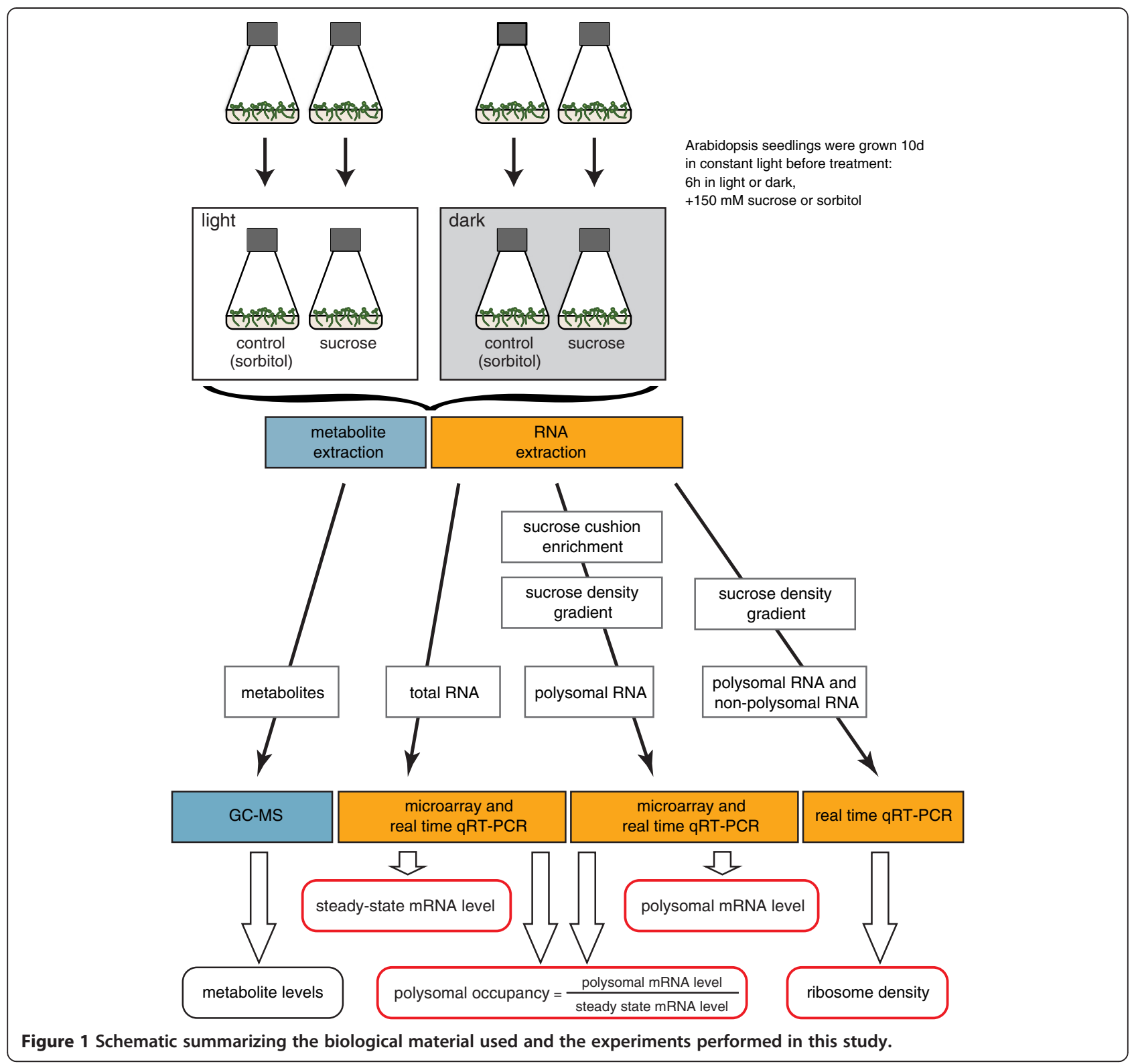

were analyzed using GC-MS (Table 1, Additional file 1: Table S1). By comparing data obtained for seedlings treated with sorbitol (control) in the dark and in the light, we could conclude that dark control treatment did not induce carbon starvation in our conditions, as sucrose and hexose levels were not significantly affected, similar to most of the identified metabolites. Interestingly, some of the metabolite levels showed a significantly different response to sucrose treatment in the light and in the dark. The levels of amino acids glycine and glutamine increased in the light but not in the dark, while valine and isoleucine decreased in the dark but not in the light. Furthermore, the sucroseinduced increase in hexose and hexose-phosphate levels was stronger in the light. While the organic acids malic acid and citric acid accumulated more in the light than in the dark, succinic acid showed higher levels in the dark. Glycerol-3-phosphate showed reduced levels in the light but not in the dark. This indicates that the sucrose treatment affected metabolism differently in the dark than in the light condition.

\section{Sucrose treatments affect transcription differentially in the light than in the dark}

Differences in transcript levels induced under the different conditions were studied using microarray analysis (Additional file 2: Table S2). When comparing the sorbitol treated controls, it became apparent that the dark treatment alone affected only few genes (358) in their steadystate level ( $\mathrm{p}<0.05$, more than 2 fold change). 99 of these genes were up-regulated and $\mathrm{GO}$ terms related to response 
Table 1 Changes of metabolite concentrations induced by sucrose treatments in the light and in the dark

\begin{tabular}{|c|c|c|c|}
\hline Metabolites & $\begin{array}{l}\text { Light sucrose compared } \\
\text { to light control }\end{array}$ & $\begin{array}{l}\text { Dark control compared } \\
\text { to light control }\end{array}$ & $\begin{array}{l}\text { Dark sucrose compared } \\
\text { to dark control }\end{array}$ \\
\hline \multicolumn{4}{|c|}{ Sugars and related compounds } \\
\hline Glycerol-3-phosphate & $0.48 *$ & 0.77 & 0.83 \\
\hline Hexoses & $186.7 *$ & 0.94 & $108.2 \diamond$ \\
\hline Hexose-6-phosphates & $2.34 *$ & 1.27 & 1.23 \\
\hline Inositol & 0.88 & 1.02 & 0.86 \\
\hline Sorbitol & $0.08 *$ & 0.98 & $0.05 \diamond$ \\
\hline Sucrose & $53.5 *$ & 1.47 & $37.4 \diamond$ \\
\hline \multicolumn{4}{|c|}{ Amino acids and derivatives } \\
\hline 4-Aminobutyric acid & 0.97 & 1.15 & 1.21 \\
\hline Alanine & 0.96 & 1.04 & 0.90 \\
\hline Arginine & 1.00 & 1.17 & 0.92 \\
\hline Asparagine & 1.33 & 1.21 & 1.08 \\
\hline Aspartic acid & 1.29 & 0.87 & 1.20 \\
\hline Glutamic acid & 1.47 & 1.22 & 1.49 \\
\hline Glutamine & $2.06 *$ & 1.12 & 1.12 \\
\hline Glycine & $10.9 *$ & 0.33 & 2.56 \\
\hline Isoleucine & 0.81 & $1.83 *$ & $0.30 \diamond$ \\
\hline Lysine & 1.06 & 1.30 & 0.93 \\
\hline O-acetylserine & 1.47 & 1.35 & 5.77 \\
\hline Ornithine & 1.06 & 1.28 & 0.95 \\
\hline Serine & $0.41 *$ & 0.82 & $0.46 \diamond$ \\
\hline Threonic acid & 1.34 & 1.09 & 0.90 \\
\hline Threonine & 0.87 & 0.78 & 0.64 \\
\hline Valine & 1.20 & 1.29 & $0.69 \diamond$ \\
\hline \multicolumn{4}{|l|}{ Organic acids } \\
\hline 4-Hydroxybenzoic acid & 0.92 & 0.98 & 0.98 \\
\hline Citric acid & $7.12 *$ & 0.99 & 2.26 \\
\hline Fumaric acid & $1.54 *$ & $0.69 *$ & $1.38 \diamond$ \\
\hline Maleic acid & 0.89 & 0.92 & 0.94 \\
\hline Malic acid & $5.67 *$ & 0.56 & $3.89 \diamond$ \\
\hline Succinic acid & 1.41 & 0.99 & $3.70 \diamond$ \\
\hline \multicolumn{4}{|l|}{ Other compounds } \\
\hline Ascorbic acid & $1.44 *$ & 0.95 & 0.98 \\
\hline Gluconic acid & 1.13 & 1.12 & $0.70 \diamond$ \\
\hline Octadecanoic acid & 0.88 & 0.97 & 0.94 \\
\hline Phosphoric acid & 0.83 & 1.33 & 0.75 \\
\hline Piperidine & 0.97 & 1.10 & 0.95 \\
\hline Putrescine & 1.18 & 1.17 & 1.17 \\
\hline t-Sinapinic acid & 0.92 & 1.09 & 0.97 \\
\hline
\end{tabular}

Values represent the average fold change of different metabolites in treated samples versus the respective control. Asterisks denote a significant difference to the light control (Student's t-test with Bonferroni correction for multiple testing, $\mathrm{p}<0.05$ ), diamond symbol denotes a significant difference to the dark control (Student's $\mathrm{t}$-test with Bonferroni correction for multiple testing, $\mathrm{p}<0.05)$. 
to sugar stimuli were found enriched. No genes related to stress response or starvation were induced by the dark control treatment providing further evidence that this treatment does not induce starvation. Among the 259 down-regulated genes, enriched GO terms were related to starch metabolism and the chloroplast, indicating that reduced polysaccharide synthesis and the remobilization of stored reserves might prevent starvation during the dark treatment.

Sugar treatment induced substantial transcriptional changes in both light and dark. In seedlings treated with sucrose under light condition, the steady state mRNA level of 2225 genes was significantly ( $<<0.05$, more than 2 fold change) changed, with 947 genes up- and 1278 downregulated compared to the light control treatment. In seedlings treated with sucrose under dark condition, the expression of 2981 genes was significantly changed, with 1474 genes up- and 1506 down-regulated compared to the dark control. Of the sugar-controlled genes, 967 responded only in the light, and 1728 only in the dark condition, and 1257 were significantly changed in both (Figure 2A, Additional file 3: Figure S1 and Additional file 4: Figure S2 for more comparisons).

The changes observed for steady-state mRNA levels in the different conditions were compared with the measured metabolic changes (Additional file 5: Figure S3). However, no clear pattern was observed that could connect the alterations on the two cellular levels, consistent with studies showing a predominant regulation of metabolism on the post-transcriptional level [35].

GO term enrichment analysis was used to identify significantly enriched functions among the genes affected in the different conditions (Figure 2B). More genes linked to stress and signaling were up-regulated by sucrose treatment in the dark, while genes expressing cytosolic ribosomal proteins were mostly up-regulated in the light. Categories those were down-regulated both in the light and in the dark contained genes involved in photosynthesis and carbohydrate metabolism.

Using the PlantGSEA toolkit for gene set enrichment analysis [36], we found an overlap between previously generated datasets and our microarray results (Additional file 6: Table S3). Genes up-regulated by sucrose treatment [37], carbon fixation [38] or repressed by the KIN10 subunit of SnRK1 [39] overlapped significantly with the list of genes induced by sucrose both in dark and in light in our study. Inversely, genes down-regulated by sucrose treatment in both conditions of our study are to a great extend also repressed by sucrose in another study [37], by carbon fixation [38] or are identified as positively affected by KIN10 [39].

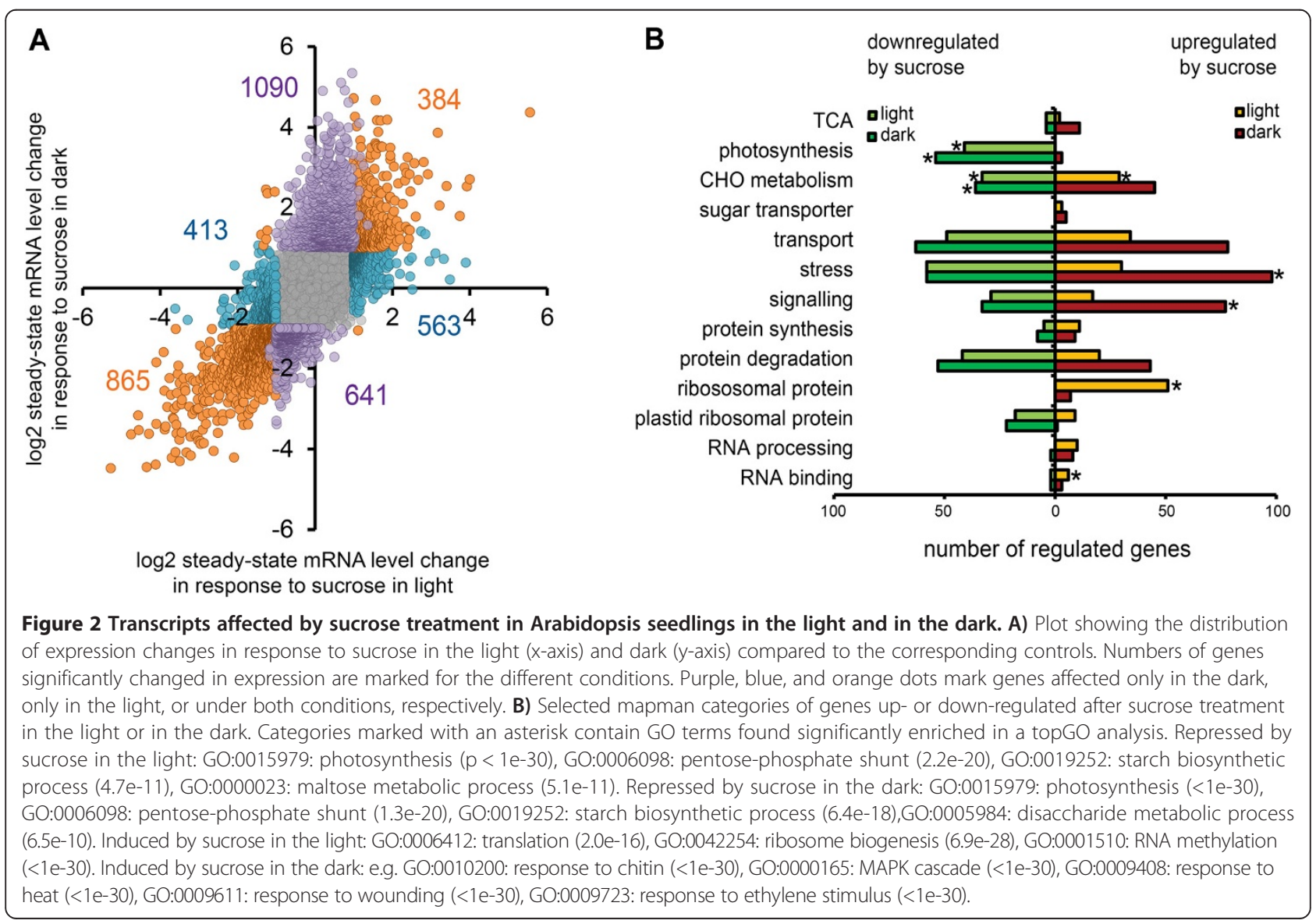


While sucrose-repressed genes showed a great overlap between the dark and the light condition, bigger differences between light and dark were observed for the genes induced by sucrose (Additional file 3: Figure S1 and Additional file 4: Figure S2). In the dark, but not in the light, the sucrose-induced genes overlapped significantly with those found induced by biotic stress response [40,41], in agreement with the enrichment of GO terms linked to stress response and signaling among these genes.

\section{Sucrose induced translational changes are different in the} light and in the dark

In order to study to what extent the changes in steadystate mRNA levels are linked to changes in translation of the mRNAs, sucrose density gradient fractionation was performed. General translational activity can be estimated from this data by analyzing the area under the curve in the polysomal fractions (Figure 3A). In the light control samples, $42 \pm 5 \%$ of the total area was in the polysome fraction. This value dropped to $37 \pm 6 \%$ in the dark-treated control, while sucrose treatment significantly increased the percentage of polysomal RNA areas to $55 \pm 6 \%$ in the light and $47 \pm 5 \%$ in the dark, which corresponds to a difference to the control of $12 \pm 4 \%$ and $11 \pm 6 \%$, respectively (Figure $3 \mathrm{~B}$ ).

In order to analyze the mRNA content by microarray, the polysomal fraction were separated from the non-polysomal fraction (Figure 3A). The polysomal fraction was separated into small and large polysomes, and the mRNA extracted from these fractions was analyzed by microarray analysis. Unexpectedly, an around 90\% overlap

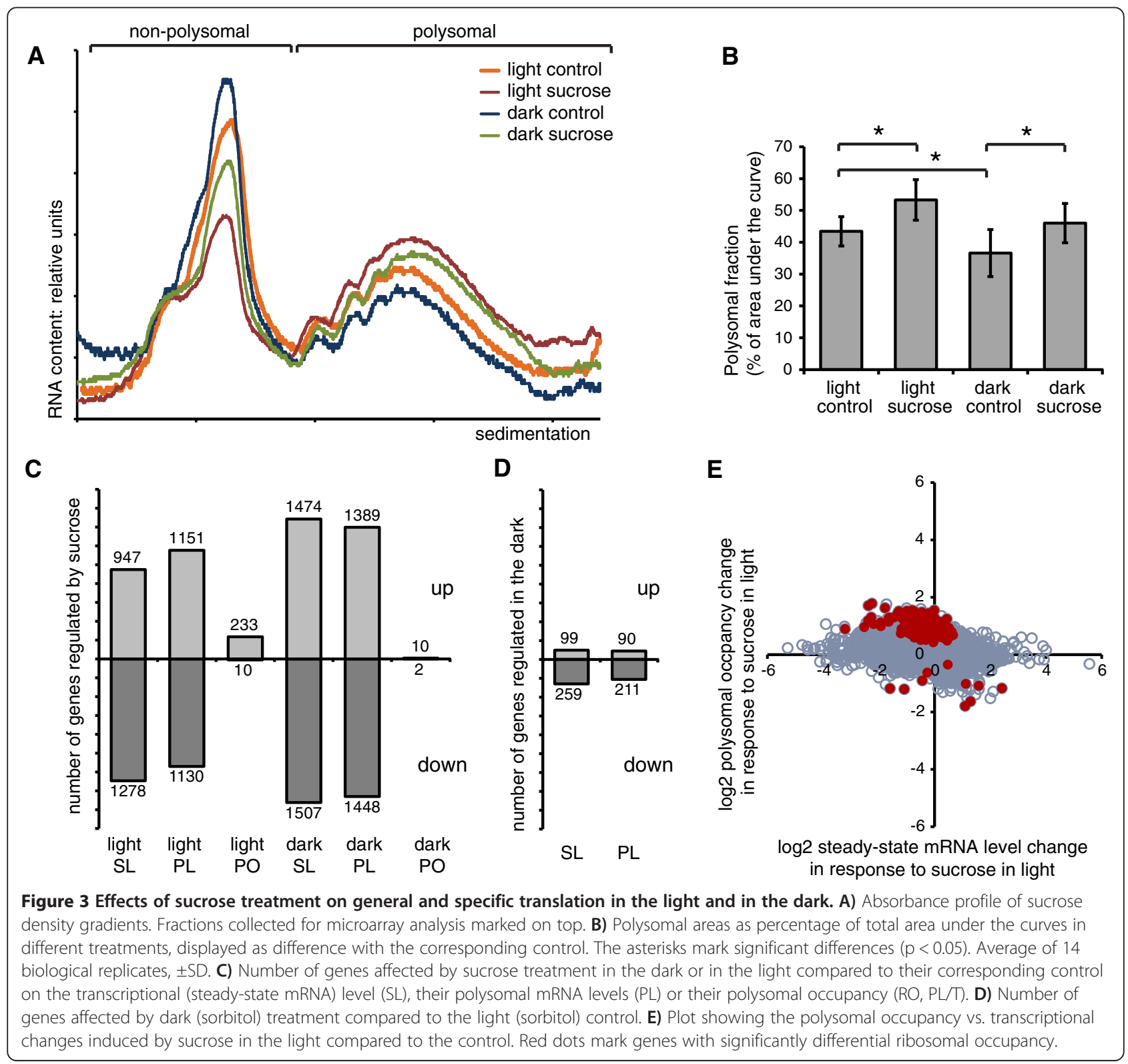


was observed between the lists of genes affected in the small or large polysome fractions after sucrose treatment. Therefore, the results obtained for the small polysome fractions are discussed here as polysomal mRNA levels in order to simplify the analysis. Comparing the polysomal mRNA levels with changes of steady-state levels allowed identifying alterations in polysomal occupancy, representing the ratio of polysomal mRNA levels to steady-state mRNA levels under the different conditions. The lists obtained for genes altered in their polysomal occupancy in small and large polysomes were fused, as only 4 genes were specific for the large polysomal fraction.

Following sucrose treatment, most mRNAs showed similar changes in steady-state and in polysomal mRNA levels (Figure 3C, Additional file 3: Figure S1 and Additional file 4: Figure S2). Interestingly, polysomal occupancy was changed for a number of genes. We identified 243 genes with altered polysomal occupancy following sucrose treatment in the light and 12 genes affected by sucrose treatment in the dark, with 7 genes found under both conditions. The dark control treatment (compared to the sorbitol light control) affected the polysomal mRNA levels of few genes and none of which was significantly affected in polysomal occupancy in our experimental conditions (Figure 3D).

Sucrose treatment induced the differential polysomal occupancy of 243 mRNAs in the light. Most of these mRNAs were relatively poorly translated in control conditions, whereas sucrose treatment promoted their polysomal mRNA levels. Interestingly, 238 of the 243 genes were detectable in the control samples of a recently published dataset obtained by ribosomal profiling of Arabidopsis seedlings [15], indicating that the genes are translated also in general conditions. For these genes, the translational efficiency under control conditions ( $1 \%$ sucrose) was markedly lower than the average of the whole dataset, indicating that these genes might be translated less than average. Furthermore, only for 31 out of the 243 transcripts the sugar treatment altered steady-state transcript levels significantly (Figure 3E).

A significant higher number, than expected from random distribution of the 243 genes, changed in polysomal occupancy following sucrose treatment in the light could be associated to GO terms related to vesicle-mediated transport, protein degradation, and ribosomal proteins (Additional file 7: Figure S4).

Sucrose treatment in the light affected both steady-state transcript levels and polysome association of ribosomal protein mRNAs. On the microarray, 228 out of the 240 genes encoding ribosomal proteins in Arabidopsis thaliana were represented, including $R A C K 1$, but excluding identified pseudogenes. Of these, steady-state levels of 199 mRNAs were significantly affected, with 44 mRNAs showing an over 2-fold response. Interestingly, the sucrose effect on polysomal mRNA levels of mRNAs encoding ribosomal proteins was more pronounced, with 212 mRNAs significantly affected and an over two-fold change of 116 mRNAs (Additional file 8: Table S4). The ribosomal protein mRNAs significantly affected in their polysomal occupancy belong to 13 of the 81 ribosomal protein gene families. Next to the mRNAs affected in polysomal occupancy, paralogs of all gene families were affected in their steady-state transcription or their polysomal mRNA levels. The RPL18a family, for example, had two paralogs (L18aA and B) not significantly affected in steady-state levels or polysome association, one paralog $(\mathrm{L} 18 \mathrm{aD})$ affected in both, and one paralog (L18aC) affected in polysomal occupancy (Figure 4). For the latter, polysomal mRNA levels were significantly affected, whereas the steady-state mRNA levels remained unaltered. The RPL18a family thus served as an example of different possible regulatory effects that were observed for the different members of a ribosomal protein family.

Interestingly, after sucrose treatment in the dark, 123 ribosomal protein mRNA steady-state levels changed significantly, with 7 mRNAs showing an over two-fold change. Furthermore, 153 mRNAs showed significant changes in polysome association, but only 3 mRNAs showed an over two-fold change. None of the ribosomal protein genes was significantly affected in its polysomal occupancy (Additional file 8: Table S4).

\section{Ribosome density is decreased after sucrose treatment}

The distribution of mRNAs between non-polysomal and polysomal fraction was investigated by real time qRT-PCR analysis of mRNA extracted from sucrose density gradient

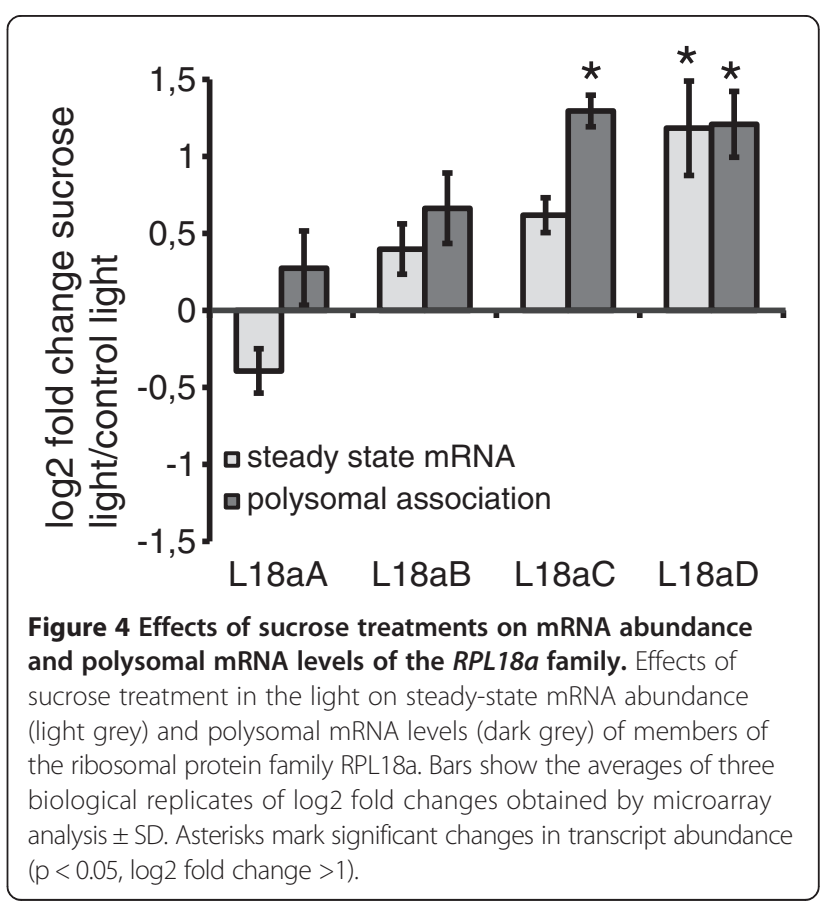


fractions without prior sucrose cushion enrichment. In this way, the total mRNA complement could be studied, including the mRNAs not associated to ribosomes that are removed by the sucrose cushion enrichment. Such experiments allow for the polysomal mRNA levels to be expressed as percentage of total mRNA. Polysomal mRNA association was analyzed for 10 different genes and using a spiked-in luciferase mRNA control for normalization. This experiment confirmed the pattern of polysomal mRNA levels observed in microarray analysis for 5 mRNAs with increased polysomal occupancy (Figure 5A) and 5 with no significant changes in occupancy, as well as the distribution of 18S rRNA (Additional file 9: Figure S5). In this way, the increased polysomal occupancy of mRNAs encoding RPS12A (At1g15930) and RPL18aC (At3g14600) was confirmed, which rose from approx. 30-40\% in the control to $>80 \%$ in the sucrose treated samples (Figure $5 \mathrm{~A}$ ). A similar pattern was observed for an RNA binding protein
(At1g73530), but not for a cytochrome P450 family member (At4g39510) as negative control, confirming results obtained in the microarray analysis.

Furthermore, dynamics of the transcripts within the polysomal fraction was studied using real time qRT-PCR analysis of 12 gradient fractions collected from sucrose density gradients loaded with sucrose cushion-enriched samples. Primers for $18 \mathrm{~S}$ rRNA were used to confirm similar distribution of rRNA in control and sucrose-treated samples after normalization with spiked-in LUC mRNA and the area under the respective curves in the sucrose density gradients (Figure 5B, Additional file 9: Figure S5). Interestingly, the mRNA peaks observed after sucrose treatment appear in a fraction of lower density compared to the control, while a shift to higher density could have been expected considering the increase in polysomal occupancy. Apparently, fewer ribosomes were loaded on a larger fraction of the mRNAs after sucrose treatment. No difference

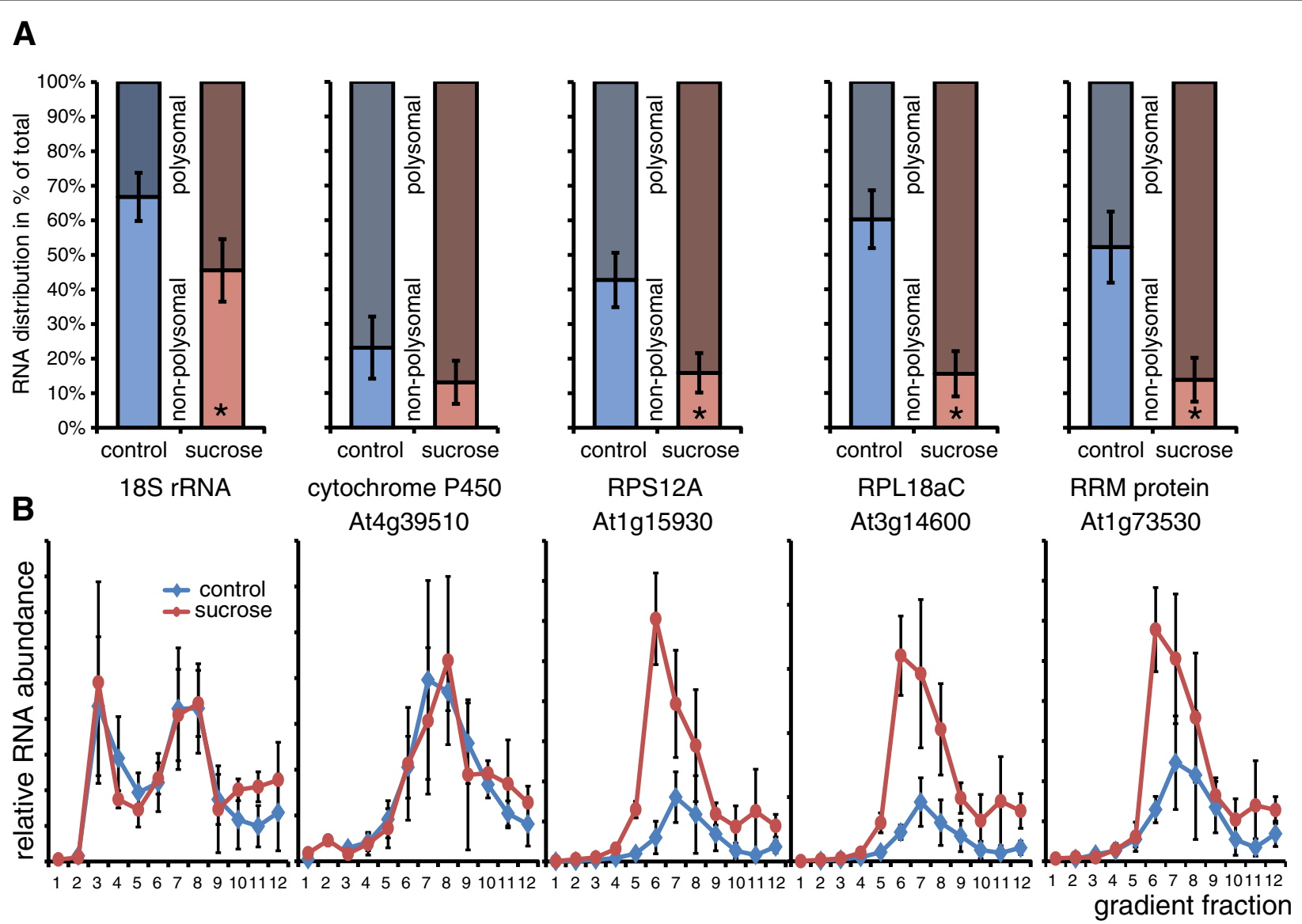

Figure 5 Real-time qRT-PCR confirmation of the results obtained by microarray analysis for samples treated with sucrose in the light. A) Comparison of the RNA distribution in non-polysomal (NP, light color) and polysomal (PL, dark color) fractions after performing sucrose gradient fractionation without prior cushion purification. Data was normalized on LUC spike-in mRNA and the sum of signal in NP and PL was set as $100 \%$. Bars show averages of 3 independent biological replicates \pm SD. Asterisk denotes significant differences between sucrose and control as determined by Student's t-test $(p<0.05)$. B) Real-time qRT-PCR analysis of gradient fractions of gradients performed after sucrose cushion enrichment of polysomes from the top (fraction 1) to the bottom of the gradient (fraction 12). Shown are averages of three independent biological replicates \pm SD, expression values normalized on LUC spike and on the total area under the curve in the corresponding polysomal gradient analysis. 
in polysomal occupancy or ribosome density was detected for the cytochrome P450 mRNA (At4g39510) used as negative control.

\section{Bioinformatic analysis reveals specific characteristics of translationally controlled mRNAs}

Bioinformatic analysis showed mRNA characteristics significantly different in the group of translationally regulated mRNAs compared to the microarray background. The sucrose-regulated mRNAs were significantly shorter in their total mRNA length, as well as in the length of the coding sequence (CDS), whereas the GC content of the 5 'UTR was significantly higher (Figure 6A,B). Analysis of the effective number of codons (Nc), which gives an indication of the codon usage bias, could not identify a significant difference between the selected group of genes and the background. The sucrose-regulated mRNAs did not contain more uORFs than the background and their AUGs did not significantly differ from the background consensus. Furthermore, secondary structure analysis did not reveal enrichment in secondary structure.

De-novo motif discovery using MEME identified a number of motifs enriched in the sequences of translationally regulated mRNAs after sucrose treatment (Table 2). Two motifs, [GA][GA]AGA[GA] and [TCA]CG[GCA]CG[GA][CA] $G$ were found enriched more than threefold (Figure $6 C$ ).

\section{Discussion}

Protein synthesis is tightly coordinated with light $[19,34]$ and energy availability $[42,43]$. In this study, we treated
Arabidopsis seedlings with sucrose in the light and in the dark with the aim to uncouple the effect of energy and light availability on the transcription and translation of mRNAs.

Comparing the light and dark control treatments, we concluded that the $6 \mathrm{~h}$ dark treatment, in our conditions, did not induce starvation responses. The majority of the measured metabolites, most importantly sucrose and hexoses, did not significantly change in abundance. Furthermore, gene expression changes did not affect stress or starvation related genes. While the dark treatment induced a decrease in polysomal mRNA association, as described before [19], this effect closely followed the gene expression changes and no alteration in polysomal occupancy was detected. Therefore, we used this dark treatment as control for the sucrose treatment in the dark in subsequent experiments, in order to distinguish the sucrose and light specific effects on transcription and translation.

Changes in sugar levels affect the expression of a large number of genes [44]. Sugar treatments repress gene expression related to photosynthesis and energy mobilization, while biogenesis of amino acids, polysaccharides, proteins, and lipids are induced $[45,46]$. These effects were confirmed here for sucrose treated seedlings under both dark and light conditions. The effect of sucrose treatment on gene expression was larger in the dark than in the light, most evident for sucrose induced genes as compared to sucrose repressed genes. Stress-related genes, for example, were more induced by sucrose in the dark than in the light. Interestingly, most genes encoding cytoplasmic

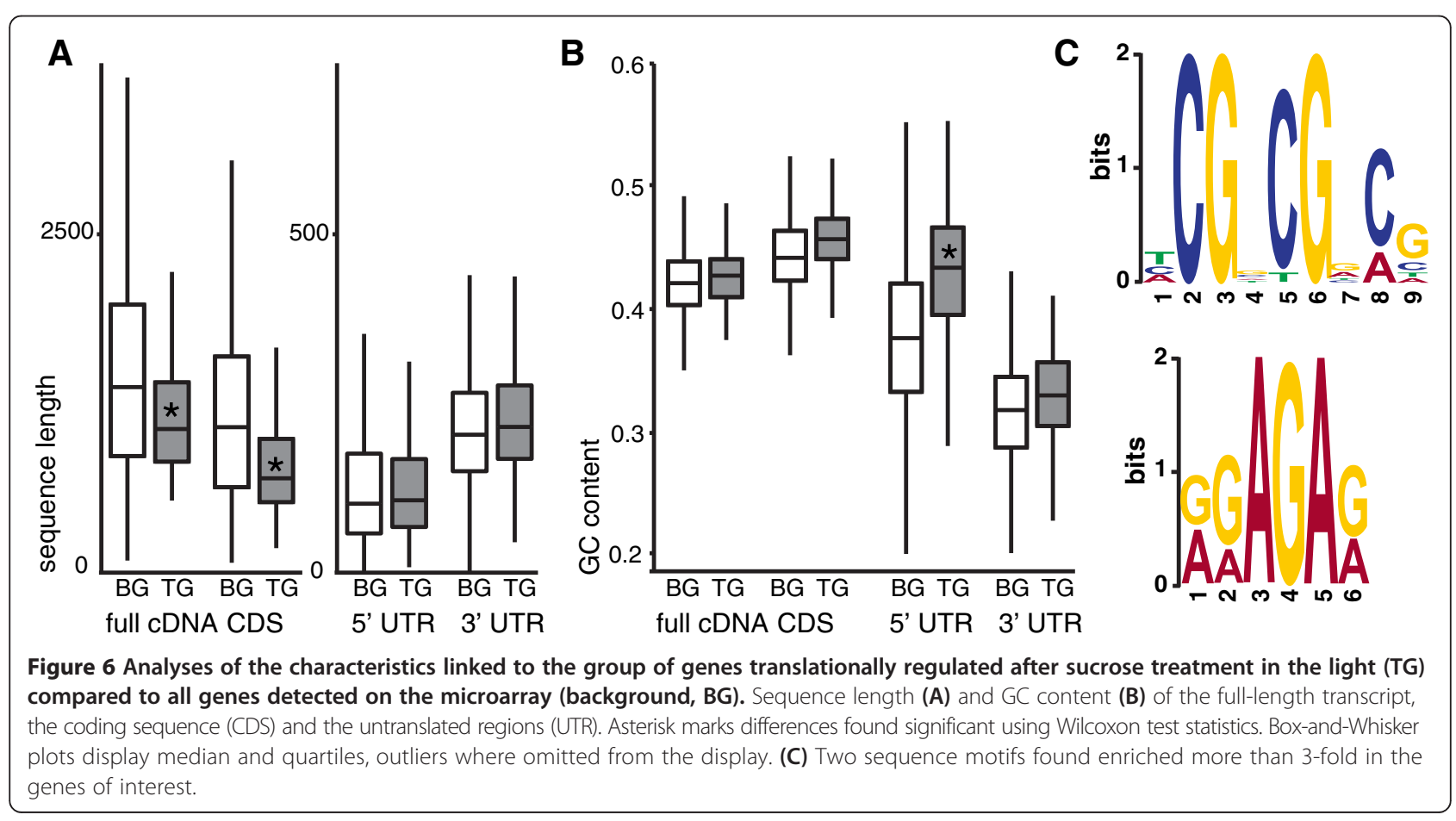


Table 2 Motifes found enriched in genes regulated on the translational level by sucrose ( 243 genes) compared to the background (19250 genes) using Fisher's exact test

\begin{tabular}{|c|c|c|c|c|c|}
\hline Consensus & Source & Translated & Background & Fold enr. & p-value \\
\hline$[\mathrm{GA}][\mathrm{GA}] \mathrm{AGA}[\mathrm{GA}]$ & 5'UTR & 29 & 784 & 3,2 & $4,6 \mathrm{E}-08$ \\
\hline $\mathrm{G}[\mathrm{AG}] \mathrm{AGAAGAA}[\mathrm{GA}]$ & 5'UTR & 72 & 3262 & 1,9 & $2,5 \mathrm{E}-08$ \\
\hline GAAGAAG[AC] & CDS & 59 & 2688 & 1,9 & $9,2 \mathrm{E}-07$ \\
\hline$C G[G A] C G[A G]$ & 5'UTR & 82 & 3413 & 2,1 & $1,9 \mathrm{E}-11$ \\
\hline$[T C A] C G[G C A] C G[G A][C A] G$ & 5'UTR & 55 & 1476 & 3,2 & $7,7 \mathrm{E}-15$ \\
\hline C[TG]TC[TG][TC]C[GT]TC & CDS & 160 & 15406 & 1,3 & $3,3 \mathrm{E}-08$ \\
\hline [CT]TСт[TC][TC][CT]TCT & CDS & 166 & 15975 & 1,4 & $7,8 \mathrm{E}-09$ \\
\hline
\end{tabular}

ribosomal proteins showed sucrose-induced expression only in the light. Ribosomal protein genes were found to be regulated by sugar availability in different studies [37-39]. The results presented here suggest that light acts as additional factor necessary for sucrose-induced expression of cytoplasmic ribosomal protein genes. We also show that polysomal occupancy can be enhanced by supplying sugar to non-starved plants.

\section{Sucrose promotes polysomal occupancy in the light}

Polysomal loading was shown to correlate with sucrose concentration in Arabidopsis seedlings [1]. Our results confirmed the general effect of sucrose on translational activity, both in constant light and during dark treatment. In both conditions, the sucrose treatment increased the area under the curve in the polysomal fractions by more than $10 \%$ compared to the corresponding control. Many mRNAs were affected in both polysomal mRNA levels and steady-state levels. However, specific changes in only one of these factors were detected for over 450 genes, suggesting translational regulation independent of mRNA levels. More specifically, sucrose treatment caused significantly different polysomal occupancy of 243 mRNAs in light and 12 in the dark, respectively. Thus, sucrose treatment alone is sufficient to induce a general increase in translation concurrent with changes in transcription, whereas light as an additional factor seems necessary to mediate the specific increase of polysomal occupancy.

\section{Ribosomal protein mRNAs are translationally regulated}

Sucrose treatment affected the steady-state levels of 201 mRNAs encoding cytosolic ribosomal proteins, the polysomal mRNA levels of 215 , and the polysomal occupancy of 13 mRNAs of the 243 cytosolic ribosomal protein genes present on the microarray. All of the 80 ribosomal protein families are affected on the transcriptional or translational level by sucrose treatment in the light. Interestingly, this regulatory pattern is absent in the dark. This adds a new layer of regulation to the proposed ribosomal protein gene translational 'regulon' model stating that ribosomal protein mRNAs are regulated concertedly at the translational level $[14,21]$. How this translational regulation is achieved remains to be discovered. In mammals, the ribosomal protein mRNAs contain an oligopyrimidine tract in their 5'UTR, the 5'-TOP motif. This motif mediates translational regulation in a mechanism probably involving the TOR kinase [47]. Although this motif has not been observed in plants, the TOR kinase was suggested to be involved in ribosomal biogenesis and the regulation of translation [48-51] and might therefore be involved in the translational regulation described here. Translational regulation could also be achieved by sugar-induced ribosome heterogeneity, as sucrose treatment was shown to affect ribosomal protein composition [31]. Some members of ribosomal protein families where shown to be enriched more than others in ribosomes extracted from sucrosetreated leaves. Furthermore, several ribosomal proteins and compounds of the translational machinery were found differentially phosphorylated dependent on photosynthetic activity [33]. This altered composition might contribute to mRNA selection by the ribosome and thus to their translational regulation [30].

\section{What is the mechanism of translational stimulation in response to sucrose treatment?}

The two parameters, polysomal occupancy and ribosome density, describe the fraction of a certain mRNA being translated and the number of ribosomes per transcript, respectively $[14,52]$. Using sucrose density gradient centrifugation, we could distinguish these two parameters. Without sucrose cushion enrichment, all ribosome bound and non-bound mRNA will be found in the sucrose density gradient. The shift from the non-polysomal to the polysomal fraction indicates an increase in polysomal occupancy, as more of the total of a transcript is associated with ribosomes [21]. Sucrose cushion enrichment of polysomes removes mRNA not bound to ribosomes. The fractions of the sucrose gradient contain transcripts with increasing numbers of bound ribosomes, thus giving an indication of ribosome density [34]. Fractions obtained using both techniques were analyzed using real time qRT-PCR for 10 
mRNAs, of which 5 were affected in their polysomal occupancy on the microarray, and 5 were not.

Polysomal occupancy determined by microarray analysis was confirmed for these 10 mRNAs in independent biological samples. The sucrose induced changes in polysomal occupancy observed by microarray analysis range between 1.3 and 3.4 fold. In the control conditions, the observed polysomal mRNA levels of the mRNAs analyzed by real time qRT-PCR was at least $40 \%$. Therefore, an increase to $\sim 80 \%$ corresponds to a two-fold change at most, agreeing with the microarray observations. For the majority of mRNAs, polysomal occupancy is probably close to the optimum in the light control condition and cannot be significantly increased by sucrose addition. Hence, changes in translational status are observed primarily for transcripts that are poorly translated in the control or show a big discrepancy between their transcriptional and translational regulation.

For the same mRNAs, ribosome density was analyzed in order to get a view on translational dynamics in the different conditions. Interestingly, we observed decreased ribosome density of the 5 transcripts with increased polysomal occupancy. A general effect of the sucrose treatment on ribosome density could be excluded, as the 5 genes with unaltered polysomal occupancy also showed unaltered ribosome density. Changes in initiation frequency, elongation speed, termination, and ribosomal recycling could lead to the observed changes in ribosome density in response to sucrose treatment (Figure 7). Initiation is considered the regulatory step of translation, and increased initiation alone would lead to an increase of both polysomal occupancy and density. However, for the group of mRNAs reported here, we observed increased polysomal occupancy but decreased ribosome density. For these mRNAs, elongation could be slower or even stalled, resulting in decreased initiation per mRNA. However, faster elongation without an increase in initiation could result in the runoff of ribosomes and would present the same shift to lower density fractions. Additionally, termination could be affected and ribosomes stalled on the mRNA. With a concurrent decrease in initiation, this would lead to the observed pattern. Finally, the ribosomal recycling could be affected in a way that could make re-initiation less efficient. Analyzing our biological material using the recently developed technique of ribosomal profiling [15,53,54] would help answering the questions concerning translational dynamics and how translation is affected after sucrose treatment. Furthermore, quantitative proteomic approaches would be necessary to connect the observed changes in polysomal occupancy and density to changes in protein synthesis.

Most of the mRNAs with increased polysomal occupancy upon sucrose treatment in the light seem to be translated less efficiently than average under control conditions. This was confirmed by real time qRT-PCR results on the nonpolysomal and polysomal fractions. The genes tested showed no more than $55 \%$ of the transcripts in the polysomal fraction, whereas this value was higher for the group of genes not affected in their polysomal occupancy. It was estimated that on average $70 \%$ of a transcript is present in polysomes [18], further underlining that the sucrose affected mRNAs were poorly translated in control conditions. The underlying mechanism remains an open question. Comparison with data obtained by immunoprecipitation of UBP1-associated mRNAs that might form granules of inactive transcripts did not identify any of the sucrose controlled genes to be UBP1 associated [16]. It is possible that another regulatory mechanism sequesters these mRNAs in the cytosol and keeps them from being efficiently translated. It remains to be understood how this sequestration might be released or how these mRNAs might be selected for translation after sucrose treatment.

Analysis of the mRNA characteristics of the transcripts affected in their polysomal occupancy by sucrose treatment in the light showed relatively short transcripts and coding sequences, as well as increased GC content in the 5'UTR compared to the background. These mRNA features are suggested to regulate translation under stress conditions $[19,55]$. Transcripts repressed in translation by dark or hypoxia treatments show a shorter than average CDSs and a higher than average GC content in the 5'UTR. It is possible that the characteristics that lead to a decrease of translation in stress conditions also limit translation

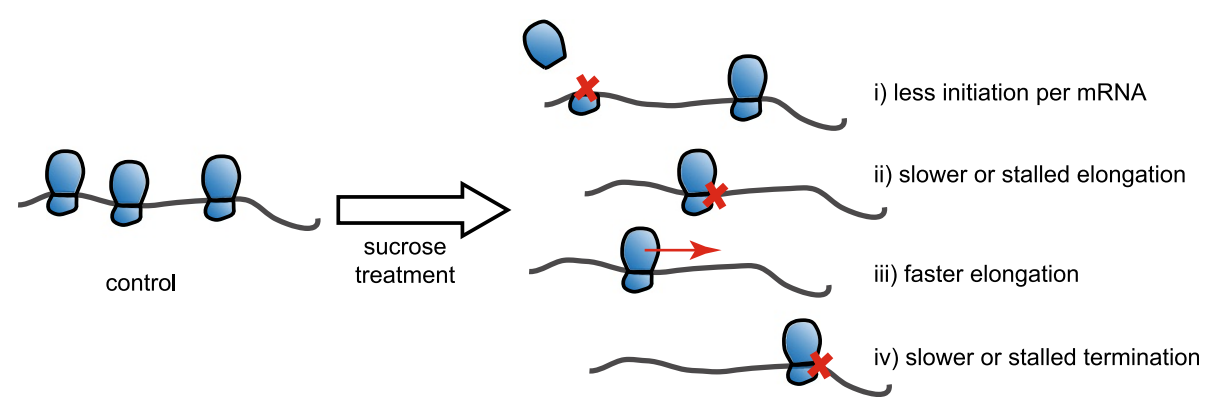

Figure 7 Schematic model summarizing the possible explanations for the observed pattern in polysomal distribution. 
efficiency under control conditions. Furthermore, two sequence motifs were found to be enriched in the 5 'UTR of these mRNAs. Whereas data on translational regulation by mRNA motifs remains scarce, such motifs might play a role in the sequestration of mRNAs in the cytosol during control condition or in the selection of the mRNAs for translation after sucrose treatment. It is noteworthy that one of the sites identified resembles the well conserved purine-rich motif found in many 5 ' leaders of six different families of dicotyledonous plants [56]. However, the motifs were found in a limited number of transcripts and can therefore not explain the mechanism of translational regulation for all the mRNAs affected in their polysomal occupancy after sucrose treatment in the light.

\section{Conclusions}

The translational stimulation in response to sucrose treatment reported here substantiates the diverse reports on plant translational regulation, underlining that several different translational control mechanisms exist in plants. We observed an increase in polysomal occupancy concurrent with decrease in ribosome density in a subset of mRNAs. Enrichment of different motifs and other sequence characters of the regulated mRNAs indicate several regulatory mechanisms operating in parallel. Further studies using both ribosomal profiling as well as specific mutant analyses are required to advance our understanding of these novel regulatory mechanisms.

\section{Methods}

\section{Biological material}

Arabidopsis seeds (var. Col-0) were sterilized in 20\% bleach for $20 \mathrm{~min}$, washed 5 times with sterile deionized water, and stratified in water at $4^{\circ} \mathrm{C}$ for 2 days. Seedlings were grown in $250 \mathrm{ml}$ Erlenmeyer bottles containing $100 \mathrm{ml} \mathrm{0.5} \mathrm{Murashige-Skoog} \mathrm{medium} \mathrm{for} 10$ days under constant shaking and in constant light at $22^{\circ} \mathrm{C}$. Flasks were covered with aluminum foil or left in the light, and treated with $150 \mathrm{mM}$ sorbitol or sucrose for six hours. Material was harvested by washing seedlings with deionized water and snap-freezing in liquid nitrogen.

\section{GC-MS metabolic analysis}

Metabolite extraction and analysis was performed with six biological replicates as described before [57] with some modifications. The samples $(10+/-1 \mathrm{mg}$ each) were extracted using $1 \mathrm{ml}$ chloroform:methanol: $\mathrm{H}_{2} \mathrm{O}$ (1:3:1) supplemented with stable isotope reference compounds for normalization between different samples (7 ng $\mathrm{\mu l}^{-1}$ each of $\left[1,2,3-{ }^{13} \mathrm{C}_{3}\right]$-myristic acid, $\left[1,2,3,4-{ }^{13} \mathrm{C}_{4}\right]$-hexadecanoic acid, $\left[2,2,3,3-{ }^{2} \mathrm{H}_{4}\right]$-succinic acid, $\left[{ }^{13} \mathrm{C}_{5},{ }^{15} \mathrm{~N}\right]$-glutamic acid, $\left[25,26,26,26,27,27,27-{ }^{2} \mathrm{H}_{7}\right]$-cholesterol, $\left[{ }^{13} \mathrm{C}_{5}\right]$-proline, $[1,2$, $\left.3,4-{ }^{13} \mathrm{C}_{4}\right]$-disodium 2-oxoglutarate, $\left[{ }^{13} \mathrm{C}_{12}\right]$-sucrose, $[2,2,3$,
3- $\left.{ }^{2} \mathrm{H}_{4}\right]$-putrescine, $\left[{ }^{2} \mathrm{H}_{6}\right]$-salicylic acid, and $\left[{ }^{13} \mathrm{C}_{6}\right]$-glucose). Extraction was performed using tungsten carbide beads (3-mm) and a vibration mill (frequency set to $30 \mathrm{~Hz}$ ) for $3 \mathrm{~min}$. After centrifugation ( $10 \mathrm{~min}, 16100 \mathrm{~g}, 4^{\circ} \mathrm{C}$ ), $200 \mu \mathrm{l}$ of each supernatant was dried in a GC vial using an evacuated centrifuge. For derivatization, $30 \mu \mathrm{l}$ of methoxyamine hydrochloride (15 mg ml $\mathrm{mg}^{-1}$ in pyridine) were added and the samples were incubated for $16 \mathrm{~h}$ at room temperature (RT) after $10 \mathrm{~min}$ shaking. Trimethylsilylation was performed with $30 \mu \mathrm{l}$ of MSTFA (N-Methyltrimethylsilyltrifluoroacetamide) and 1\% TMCS (Trimethylchlorosilane) and incubation for $1 \mathrm{~h}$ at RT after $1 \mathrm{~min}$ shaking. Samples were diluted with $30 \mu \mathrm{l}$ of heptane containing $15 \mathrm{ng} \mathrm{ul}^{-1}$ methylstearate as internal control before analysis by GCTOFMS (Gas Chromatography-Time of Flight Mass Spectrometer) as described before [57].

Blank control samples and an n-alkanes series (C12-C40) for calculation of retention indices [58] were measured together with the samples. Using an PAL systems auto sampler (Agilent, Atlanta), $1 \mu \mathrm{l}$ of each sample was injected splitless into an Agilent 7890A gas chromatograph (Agilent, Atlanta) equipped with a $30 \mathrm{~m} \times 0.25 \mathrm{~mm}$ (internal diameter) fused silica capillary column with chemically bonded 0.25- $\mu \mathrm{m}$ DB 5-MS stationary phase (Agilent, Atlanta). The injector temperature was $260^{\circ} \mathrm{C}$, the septum purge flow rate was $20 \mathrm{ml} \mathrm{min}^{-1}$, and the purge was turned on after $75 \mathrm{~s}$. The gas flow rate through the column was $1 \mathrm{ml} \mathrm{min}{ }^{-1}$. The column temperature was held at $70^{\circ} \mathrm{C}$ for 2 min initially before it was increased by $20^{\circ} \mathrm{C} \mathrm{min}^{-1}$ to $320^{\circ} \mathrm{C}$ and held at $320^{\circ} \mathrm{C}$ for $14 \mathrm{~min}$. The column effluent was introduced into the ion source of a Pegasus HT TOFMS (Leco Corp., St Joseph, Michigan) using a transfer line temperature of $250^{\circ} \mathrm{C}$ and an ion source temperature of $200^{\circ} \mathrm{C}$. Ions were generated by a $-70 \mathrm{eV}$ electron beam at an ionization current of $2.0 \mathrm{~mA}$ and 20 spectra s$^{-1}$ were recorded in the mass range $50-800 \mathrm{~m} \mathrm{z}^{-1}$. The acceleration voltage was turned on after a solvent delay of $290 \mathrm{~s}$. The detector voltage was $1600 \mathrm{~V}$.

Non-processed MS files were exported into MATLAB 8.2 (R2013b; Math Works Natick, Massachusetts), in which all data pretreatment procedures (baseline correction, chromatogram alignment, and hierarchical multivariate curve resolution), were performed using custom scripts [59]. Peak integration and identification by comparing mass spectra and chromatographic retention indices of detected peaks with Umeå Plant Science Center in-house MS library entries and entries of the MS library of the Max Planck Institute in Golm (http://csbdb.mpimp-golm.mpg.de/csbdb/ gmd/gmd.html) were done with in-house scripts and NIST MS-Search version 2.0 (NIST, Gaithersburg, MD). Sample peak areas were normalized with the first score vector (t1) derived from a principal component analysis model performed with peak areas of the internal standards reference compounds which were added to the extraction mixture 
(i.e. all peak areas of one sample were divided by the corresponding $\mathrm{t} 1$-value of the respective sample). Additional, sample peak areas were normalized with the sample weights [59].

\section{Polysome gradients}

Ribosomes and ribosome-bound mRNA were extracted and separated over sucrose gradient as described before [60]. Approximately $10 \mathrm{ml}$ of powdered plant material were extracted using $20 \mathrm{ml}$ polysome extraction buffer PEB (0.2 M Tris, $\mathrm{pH}$ 9.0, 0.2 M KCl, 0.025 M EGTA, 0.035 M $\mathrm{MgCl} 2,1 \%$ Brij-35, 1\% Triton X-100, 1\% Igepal CA 630, 1\% Tween 20, 1\% PTE, $5 \mathrm{mM}$ DTT, $50 \mathrm{mg} / \mathrm{mL}$ Cycloheximide, $50 \mathrm{mg} / \mathrm{mL}$ Chloramphenicol, $80 \mathrm{mM}$ betaglycerophosphate, $1 \mathrm{mM}$ Sodium Molybdate, protease inhibitor cocktail (Sigma Aldrich), phosphatase inhibitor cocktail 3 (Sigma Aldrich)) and the extract was cleared by filtering through Miracloth ${ }^{\mathrm{Tm}}$ and centrifugation. An aliquot of $500 \mu \mathrm{l}$ was taken for total mRNA extraction; the extracts were loaded on top of a sucrose cushion (1.75 M sucrose in PEB without detergents) and centrifuged (18 h, $90000 \mathrm{~g}$ ) in a Beckman Ti70 rotor. The resulting pellet was taken up in wash buffer $(0.2 \mathrm{M}$ Tris, $\mathrm{pH} 9.0,0.2 \mathrm{M} \mathrm{KCl}, 0.025 \mathrm{M}$ EGTA, $0.035 \mathrm{M} \mathrm{MgCl2,} 5 \mathrm{mM}$ DTT, $50 \mathrm{mg} / \mathrm{mL}$ Cycloheximide, $50 \mathrm{mg} / \mathrm{mL}$ Chloramphenicol, $80 \mathrm{mM}$ betaglycerophosphate, $1 \mathrm{mM}$ Sodium Molybdate) and loaded on a 20-60\% sucrose gradient. After ultracentrifugation $(1.5 \mathrm{~h}, 190000 \mathrm{~g})$ in a Beckman Sw55Ti rotor, the gradients were fractionated into 12 fractions using a Teledyne Isco Density Gradient Fractionation System with online detection of $A_{254}$. These fractions were used separately or pooled into three samples containing non-polysomal material, small polysomes and large polysomes. Areas under the curves were calculated after subtracting the baseline obtained by measuring a blank gradient and normalizing to total area under the curve to account for possible uneven loading of the gradients. When no cushion enrichment step was performed, $1 \mathrm{ml}$ of packed material was extracted with $1 \mathrm{ml}$ of polysome extraction buffer as described above. Extract was filtered and centrifuged before loading of $750 \mu \mathrm{l}$ directly on $20-60 \%$ sucrose gradients. Ultracentrifugation and fractionation were performed as described.

\section{RNA extraction}

RNA was extracted using Guanidine- $\mathrm{HCl}$ extraction, followed by a clean-up step using the Spectrum Plant Total RNA Kit (Sigma Aldrich). To each sample (single or pooled fractions), $50 \mathrm{pg}$ of luciferase RNA was added prior to mRNA extraction to allow normalization independent of the original RNA content of the sample.

\section{Microarray}

Microarray analysis was performed in 3 biological replicates using Affymetrix GeneChips Arabidopsis AGRONOMICS
Genome Arrays by ServiceXS, Leiden, The Netherlands. Labeled sense stranded cDNA was synthesized with the Ambion WT Expression kit using 100 ng RNA. Fragmentation and terminal labeling with $5.5 \mu \mathrm{g}$ sscDNA was performed using the Affymetrix Terminal Labeling Kit. Nanodrop and BioAnalyzer were used to assess the concentration and the quality of the cRNA and fragmented sscDNA. $5.5 \mu \mathrm{g}$ fragmented sscDNA were used for hybridization on the Affymetrix GeneChips Arabidopsis AGRONOMICS Genome Array. Hybridization, washing, and staining were performed with the GeneChip Hybridization, Wash and Stain Kit. Affymetrix GeneChip Command Console (v3.1) software was used to operate the Affymetrix fluidics stations and the scanned array images were analyzed using Affymetrix Command Console Viewer software. The GeneChip data were analyzed using the $\mathrm{R}$ statistical programming environment and the Bioconductor packages [61-64]. The aroma.affymetrix package was used to perform RMA background correction, normalization, probe summarization, and quality check of the data. The LIMMA package was used to obtain gene expression data [63]. Steady-state mRNA alterations were calculated using the ratio between the values obtained for total RNA in the sucrose treatment with the corresponding control (light or dark). Polysome association alterations were calculated using the ratio between the values obtained for polysomal RNA in the sucrose treatment with the corresponding control (light or dark). Polysomal occupancy alterations were calculated using the ratio between the polysome association and the steady-state levels. p-values were adjusted for multiple testing with the Benjamini and Hochberg method [61]. GO-term enrichment analysis was performed using the topGO package.

Microarray analysis was performed for three fractions of the sucrose density gradient (non-polysomal, small and large polysome). However, as the non-polysomal fraction contained much less RNA than the others, data obtained for these samples was not used in background correction and normalization to avoid the introduction of artifacts. Furthermore, initial analyses revealed that the list of genes found affected in small and large polysomes were nearly identical. Therefore, data for the small polysomal fraction was used to represent the polysomal fraction. Raw data is deposited along with description of the experimental setup in the GEO repository under the accession nr: GSE59306.

\section{Real time qRT-PCR}

After DNase1 treatment (Thermo Scientific), cDNA was synthesized using the RevertAid Reverse Transcriptase (Thermo Scientific). Quantitative real-time PCR was performed using Power SYBR Green (Applied Biosystems) in a $5 \mu \mathrm{l}$ reaction using the standard program of a $\mathrm{ViiA}^{\mathrm{ra}} 7 \mathrm{in}$ strument (Applied Biosystems). Data was extracted using $\mathrm{ViiA}^{\mathrm{TM}} 7$ Software v1.1. Primer amplification efficiency was 
calculated using LinRegPCR [65]. Primers used are listed in Additional file 10: Table S5. Results for the primer recognizing the luciferase RNA spike were used to normalize real time qRT-PCR data and the values obtained from gradient fraction samples were reported to the area under the corresponding gradient $A_{254}$ curve to adjust for different RNA contents of the samples before extraction.

\section{Bioinformatic analysis}

Both short and long DNA motifs (4-6 and 8-10 nucleotides, respectively) were analyzed in full transcripts, CDS, 5'UTR and 3'UTR (when the corresponding annotation was available) using MEME [66]. Background dinucleotide frequencies were provided separately for each sequence type. To test specificity of the resulting motifs, FIMO [66] was used to scan all genes represented on the microarray for motif hits in the corresponding sequence type. Motifs with FIMO p-value $\leq 0.001$ (short motifs) or $\leq 0.0001$ (longer motifs) were considered significant. Motif enrichment was computed using motif counts for gene lists versus the background using a one-tailed Fisher's exact test. The distribution of sequence length, codon bias scores [67] and GC content in full transcript, CDS, 5'UTR, and 3'UTR, as well as enrichment for uORFs [68] using Fisher's exact test, and the analysis of sequence context $(-5$ to +8$)$ of the UORFs and main ORF start codon were performed using custom scripts comparing the gene list against the background.

\section{Additional files}

Additional file 1: Table S1. Changes in metabolite concentrations induced by sucrose treatments in the light and in the dark. Values represent the relative peak areas observed for the different metabolites. Asterisks denote a significant difference to the light control, diamond symbol denotes a significant difference to the dark control (Student's t-test with Bonferroni correction for multiple testing, $p<0.05$ ).

Additional file 2: Table S2. Microarray data of steady-state mRNA levels, polysomal mRNA levels, and polysomal occupancy for all the genes on the array. Genes with a fold change $>2$ for their expression values and a corrected $p$-value $<0.05$ are marked in the list.

Additional file 3: Figure S1. Venn diagrams depicting the overlap of gene lists obtained by data analysis of microarrays. A) sucrose induced steady-state mRNA changes. B) sucrose induced polysomal mRNA levels changes. C) sucrose induced changes of steady-state mRNA levels and polysomal mRNA levels in the light. D) sucrose induced changes of steadystate mRNA levels and polysomal mRNA levels in the dark. E) sucrose induced changes of polysomal occupancy and steady-state mRNA levels in the light. F) polysomal occupancy changes in the dark and in the light.

Additional file 4: Figure S2. Plots showing the polysomal association vs. transcriptional changes induced by sucrose in the light (A), in the dark (B), or by dark alone (C) compared to the corresponding control. Yellow points mark genes significantly affected ( $p<0.05$, more than 2 -fold change) in steady state mRNA level, red circles mark genes significantly affected in their polysomal association, and black crosses genes significantly affected $(p<0.05)$ in their ribosome occupancy.

Additional file 5: Figure S3. Mapman analysis of steady-state mRNA changes compared to the changes in metabolite concentrations measured by GC-MS. Changes induced by sucrose in the light A) and in the dark B), as well as by the dark treatment alone $\mathrm{C}$ ) are displayed on the Mapman output for the TCA cycle. Significantly affected metabolite concentrations are shown using up- and downward pointing arrows next to the depicted metabolite.

Additional file 6: Table S3. Summary of PlantGSEA results for lists of genes up- and down-regulated by sucrose treatment in the light or in the dark. Displayed is the overlap of the gene lists with published studies from the database obtained by the standard settings of the website.

Additional file 7: Figure S4. Functional analysis of genes found affected in their polysomal occupancy after sucrose treatment in the light. Mapman functional categories found for 154 genes changed in translational loading after sucrose treatment in the light. Not included in the chart were 44 genes without ontology and 45 that fall in miscellaneous groups. Categories marked with an asterisk (*) contained $\mathrm{GO}$ terms found significantly enriched in topGO analysis.

Additional file 8: Table S4. Changes in steady-state mRNA, polysomal mRNA levels, and polysomal occupancy induced by sucrose in the paralogs of ribosomal proteins. Log-fold changes $>1$ and p-values $<0.05$ are marked in color.

Additional file 9: Figure S5. Real time qRT-PCR confirmation of the results obtained by microarray analysis for samples treated with sucrose in the light. Bar charts: Comparison of the RNA distribution in non-polysomal (light grey) and polysomal (dark grey) fractions after performing sucrose gradient fractionation without prior cushion purification. Data was normalized on LUC spike-in mRNA and the sum of signal in NP and PL was set as $100 \%$. Bars show averages of 3 independent biological replicates \pm SD. Asterisk denotes significant differences between sucrose and control as determined by Student's t-test $(p<0.05)$. Line charts: GPCR analysis of gradient fractions of gradients performed after sucrose cushion enrichment of polysomes from the top (fraction 1) to the bottom of the gradient (fraction 12). Shown are averages of three independent biological replicates \pm SD, expression values normalized on LUC spike and on the total area under the curve in the corresponding gradient analysis.

Additional file 10: Table S5. Primer sequences used for real time qRT-PCR.

\section{Competing interests}

The authors declare that they have no competing interests.

\section{Authors' contributions}

MG conceived, performed, and analyzed most of the experiments presented in this study and drafted the first version of this manuscript. AP and BS conducted the bioinformatics analysis. AH was responsible for the metabolomics analysis. SS was involved in planning of the manuscript and helped to draft the manuscript. JH was responsible for conception and design of the study, analysis and interpretation of data, and drafting or revising the manuscript. All authors read and approved the final manuscript.

\section{Acknowledgements}

Financial support came from the Marie Curie ITN project MERIT, Grant Agreement number 264474. We thank Bio4Energy, a Strategic Research Environment appointed by the Swedish government, for supporting this work. The authors are grateful for excellent experimental support from the Swedish Metabolomics Centre.

\section{Author details}

${ }^{1}$ Molecular Plant Physiology, Institute of Environmental Biology, Utrecht University, Utrecht, The Netherlands. ${ }^{2}$ Theoretical Biology and Bioinformatics, Department of Biology, Faculty of Science, Utrecht University, Utrecht, The Netherlands. ${ }^{3}$ Umeå Plant Science Centre, Department of Plant Physiology, Umeå University, SE-90187 Umeå, Sweden.

Received: 22 July 2014 Accepted: 27 October 2014

Published online: 18 November 2014

\section{References}

1. Pal SK, Liput M, Piques M, Ishihara H, Obata T, Martins MCM, Sulpice R, van Dongen JT, Fernie AR, Yadav UP, Lunn JE, Usadel B, Stitt M: Diurnal changes of polysome loading track sucrose content in the rosette of wild-type arabidopsis and the starchless pgm mutant. Plant Physiol 2013, 162:1246-1265. 
2. Stitt M: Progress in understanding and engineering primary plant metabolism. Curr Opin Biotechnol 2012, 24:229-238.

3. Kapp LD, Lorsch JR: The molecular mechanics of eukaryotic translation. Annu Rev Biochem 2004, 73:657-704.

4. Ma XM, Blenis J: Molecular mechanisms of mTOR-mediated translational control. Nat Rev Mol Cell Biol 2009, 10:307-318.

5. Jackson RJ, Hellen CUT, Pestova TV: The mechanism of eukaryotic translation initiation and principles of its regulation. Nat Rev Mol Cell Biol 2010, 11:113-127.

6. Kawaguchi R, Bailey-Serres J: Regulation of translational initiation in plants. Curr Opin Plant Biol 2002, 5:460-465.

7. Esposito AM, Mateyak M, He D, Lewis M, Sasikumar AN, Hutton J, Copeland PR, Kinzy TG: Eukaryotic polyribosome profile analysis. J Vis Exp 2010, 40:e1948.

8. Kawaguchi R, Girke T, Bray E a, Bailey-Serres J: Differential mRNA translation contributes to gene regulation under non-stress and dehydration stress conditions in Arabidopsis thaliana. Plant J 2004, 38:823-839.

9. Branco-Price C, Kawaguchi R, Ferreira RB, Bailey-Serres J: Genome-wide analysis of transcript abundance and translation in Arabidopsis seedlings subjected to oxygen deprivation. Ann Bot 2005, 96:647-660.

10. Branco-Price C, Kaiser K a, Jang CJH, Larive CK, Bailey-Serres J: Selective mRNA translation coordinates energetic and metabolic adjustments to cellular oxygen deprivation and reoxygenation in Arabidopsis thaliana. Plant J 2008, 56:743-755.

11. Matsuura H, Ishibashi Y, Shinmyo A, Kanaya S, Kato K: Genome-wide analyses of early translational responses to elevated temperature and high salinity in Arabidopsis thaliana. Plant Cell Physiol 2010, 51:448-462.

12. Ueda K, Matsuura H, Yamaguchi M, Demura T, Kato K: Genome-wide analyses of changes in translation state caused by elevated temperature in Oryza sativa. Plant Cell Physiol 2012, 53:1481-1491.

13. Bailey-Serres J, Sorenson R, Juntawong P: Getting the message across: cytoplasmic ribonucleoprotein complexes. Trends Plant Sci 2009, 14:443-453.

14. Roy B, von Arnim AG: Translational regulation of cytoplasmic mRNAs. Arab B 2013, 11:e0165.

15. Juntawong P, Girke T, Bazin J, Bailey-Serres J: Translational dynamics revealed by genome-wide profiling of ribosome footprints in Arabidopsis. Proc Natl Acad Sci U S A 2014, 111:E203-E212.

16. Sorenson R, Bailey-Serres J: Selective mRNA sequestration by OLIGOURIDYLATE-BINDING PROTEIN 1 contributes to translational control during hypoxia in Arabidopsis. Proc Natl Acad Sci U S A 2014 111:2373-2378.

17. Nicolaï M, Roncato MA, Canoy AS, Rouquié D, Sarda X, Freyssinet G, Robaglia C: Large-scale analysis of mRNA translation states during sucrose starvation in Arabidopsis cells identifies cell proliferation and chromatin structure as targets of translational control. Plant Physio/ 2006, 141:663-673.

18. Piques M, Schulze WX, Höhne M, Usadel B, Gibon Y, Rohwer J, Stitt M: Ribosome and transcript copy numbers, polysome occupancy and enzyme dynamics in Arabidopsis. Mol Syst Biol 2009, 5:314

19. Juntawong P, Bailey-Serres J: Dynamic light regulation of translation status in Arabidopsis thaliana. Front Plant Sci 2012, 3:66.

20. Jiménez-López S, Mancera-Martínez E, Donayre-Torres A, Rangel C, Uribe L, March S, Jiménez-Sánchez G, Sánchez de Jiménez E: Expression profile of maize (Zea mays L.) embryonic axes during germination: translational regulation of ribosomal protein mRNAs. Plant Cell Physiol 2011, 52:1719-1733.

21. Tiruneh BS, Kim B-H, Gallie DR, Roy B, von Arnim AG: The global translation profile in a ribosomal protein mutant resembles that of an elF3 mutant. BMC Biol 2013, 11:123.

22. Barakat A, Szick-Miranda K, Chang I-F, Guyot R, Blanc G, Cooke R, Delseny M, Bailey-Serres J: The organization of cytoplasmic ribosomal protein genes in the Arabidopsis genome 1. Plant Physiol 2001, 127:398-415.

23. Carroll AJ, Heazlewood JL, Ito J, Millar AH: Analysis of the Arabidopsis cytosolic ribosome proteome provides detailed insights into its components and their post-translational modification. Mol Cell Proteomics 2008, 7:347-369.

24. Chang I, Szick-Miranda K, Pan S, Bailey-Serres J: Proteomic characterization of evolutionarily conserved and variable proteins of Arabidopsis cytosolic ribosomes. Plant Physiol 2005, 137(March):848-862.

25. Giavalisco P, Wilson D, Kreitler T, Lehrach H, Klose J, Gobom J, Fucini P: High heterogeneity within the ribosomal proteins of the Arabidopsis thaliana 80 S ribosome. Plant Mol Biol 2005, 57:577-591.
26. Mcintosh KB, Bonham-Smith PC: Ribosomal protein gene regulation: what about plants? Can J Bot 2006, 362:342-362.

27. Degenhardt RF, Bonham-Smith PC: Transcript profiling demonstrates absence of dosage compensation in Arabidopsis following loss of a single RPL23a paralog. Planta 2008, 228:627-640.

28. Schippers JHM, Mueller-Roeber B: Ribosomal composition and control of leaf development. Plant Sci 2010, 179:307-315.

29. Byrne ME: A role for the ribosome in development. Trends Plant Sci 2009, 14:512-519.

30. Xue S, Barna M: Specialized ribosomes: a new frontier in gene regulation and organismal biology. Nat Rev Mol Cell Biol 2012, 13:355-369.

31. Hummel M, Cordewener JHG, de Groot JCM, Smeekens S, America AHP Hanson J: Dynamic protein composition of Arabidopsis thaliana cytosolic ribosomes in response to sucrose feeding as revealed by label free MSE proteomics. Proteomics 2012, 12:1024-1038.

32. Turkina MV, Klang Årstrand H, Vener AV: Differential phosphorylation of ribosomal proteins in Arabidopsis thaliana plants during day and night. PLOS ONE 2011, 6:e29307

33. Boex-Fontvieille E, Daventure M, Jossier M, Zivy M, Hodges M, Tcherkez G: Photosynthetic control of Arabidopsis leaf cytoplasmic translation initiation by protein phosphorylation. PLOS ONE 2013, 8:e70692.

34. Liu M-J, Wu S-H, Chen H-M, Wu S-H: Widespread translational contro contributes to the regulation of Arabidopsis photomorphogenesis. Mol Syst Biol 2012, 8:566.

35. Gibon Y, Blaesing OE, Hannemann J, Carillo P, Ho M, Palacios N, Cross J, Selbig J, Stitt M: A robot-based platform to measure multiple enzyme activities in arabidopsis using a set of cycling assays : comparison of changes of enzyme activities and transcript levels during diurnal cycles and in prolonged darkness. Plant Cell 2004, 16(December):3304-3325.

36. Yi X, Du Z, Su Z: PlantGSEA: a gene set enrichment analysis toolkit for plant community. Nucleic Acids Res 2013, 41:W98-W103.

37. Gonzali S, Loreti E, Solfanelli C, Novi G, Alpi A, Perata P: Identification of sugar-modulated genes and evidence for in vivo sugar sensing in Arabidopsis. J Plant Res 2006, 119:115-123.

38. Usadel B, Bläsing $O E$, Gibon $Y$, Retzlaff $K$, Höhne M, Günther M, Stitt M: Global transcript levels respond to small changes of the carbon status during progressive exhaustion of carbohydrates in Arabidopsis rosettes. Plant Physiol 2008, 146:1834-1861.

39. Baena-González E, Rolland F, Thevelein JM, Sheen J: A central integrator of transcription networks in plant stress and energy signalling. Nature 2007, 448:938-942.

40. Ramonell K, Berrocal-Lobo M, Koh S, Wan J, Edwards H, Stacey G, Somerville S: Loss-of-function mutations in chitin responsive genes show increased susceptibility to the powdery mildew pathogen Erysiphe cichoracearum. Plant Physiol 2005, 138(June):1027-1036.

41. Wan J, Zhang X-C, Neece D, Ramonell KM, Clough S, Kim S-Y, Stacey MG, Stacey G: A LysM receptor-like kinase plays a critical role in chitin signaling and fungal resistance in Arabidopsis. Plant Cell 2008, 20:471-481.

42. Robaglia C, Thomas M, Meyer C: Sensing nutrient and energy status by SnRK1 and TOR kinases. Curr Opin Plant Biol 2012, 15:301-307.

43. Xiong $Y$, Sheen J: TOR Signaling Networks in Plant Growth and Metabolism. Plant Physiol 2014, 164:499-512.

44. Rolland F, Baena-Gonzalez E, Sheen J: Sugar sensing and signaling in plants: conserved and novel mechanisms. Annu Rev Plant Biol 2006, 57:675-709.

45. Koch KE: Carbohydrate-Modulated Gene Expression in Plants. Annu Rev Plant Physiol Plant Mol Biol 1996, 47:509-540.

46. Osuna D, Usadel B, Morcuende R, Gibon Y, Bläsing OE, Höhne M, Günter M, Kamlage $B$, Trethewey $R$, Scheible W-R, Stitt M: Temporal responses of transcripts, enzyme activities and metabolites after adding sucrose to carbon-deprived Arabidopsis seedlings. Plant J 2007, 49:463-491.

47. Thoreen CC, Chantranupong L, Keys HR, Wang T, Gray NS, Sabatini DM: A unifying model for mTORC1-mediated regulation of mRNA translation. Nature 2012, 485:109-113.

48. Deprost D, Truong H-N, Robaglia C, Meyer C: An Arabidopsis homolog of RAPTOR/KOG1 is essential for early embryo development. Biochem Biophys Res Commun 2005, 326:844-850.

49. Ren M, Qiu S, Venglat P, Xiang D, Feng L, Selvaraj G, Datla R: Target of rapamycin regulates development and ribosomal RNA expression through kinase domain in Arabidopsis. Plant Physiol 2011, 155:1367-1382 
50. Xiong Y, McCormack M, Li L, Hall Q, Xiang C, Sheen J: Glucose-TOR signalling reprograms the transcriptome and activates meristems. Nature 2013, 496:181-186.

51. Schepetilnikov M, Dimitrova M, Mancera-Martínez E, Geldreich A, Keller M, Ryabova L: TOR and S6K1 promote translation reinitiation of uORFcontaining mRNAs via phosphorylation of elF3h. EMBO J 2013, 32:1087-1102.

52. Perry RP: Balanced production of ribosomal proteins. Gene 2007, 401:1-3.

53. Liu M-J, Wu S-H, Wu J-F, Lin W-D, Wu Y-C, Tsai T-Y, Tsai H-L, Wu S-H: Translational landscape of photomorphogenic Arabidopsis. Plant Cell 2013, 25:3699-3710.

54. Ingolia NT: Ribosome profiling: new views of translation, from single codons to genome scale. Nat Rev Genet 2014, 15:205-213.

55. Kawaguchi R, Bailey-Serres J: mRNA sequence features that contribute to translational regulation in Arabidopsis. Nucleic Acids Res 2005, 33:955-965.

56. Vaughn JN, Ellingson SR, Mignone F, von Arnim A: Known and novel posttranscriptional regulatory sequences are conserved across plant families. RNA 2012, 18:368-384

57. Gullberg J, Jonsson P, Nordström A, Sjöström M, Moritz T: Design of experiments: an efficient strategy to identify factors influencing extraction and derivatization of Arabidopsis thaliana samples in metabolomic studies with gas chromatography/mass spectrometry. Anal Biochem 2004, 331:283-295.

58. Schauer N, Steinhauser D, Strelkov S, Schomburg D, Allison G, Moritz T, Lundgren K, Roessner-Tunali U, Forbes MG, Willmitzer L, Fernie AR, Kopka J: GC-MS libraries for the rapid identification of metabolites in complex biological samples. FEBS Lett 2005, 579:1332-1337.

59. Jonsson P, Johansson Al, Gullberg J, Trygg J, a J, Grung B, Marklund S, Sjöström M, Antti H, Moritz T: High-throughput data analysis for detecting and identifying differences between samples in GC/MS-based metabolomic analyses. Anal Chem 2005, 77:5635-5642.

60. Mustroph A, Juntawong P, Bailey-Serres J: Isolation of Plant Polysomal mRNA by Differential Centrifugation and Ribosome Immunopurification Methods. In Plant Syst Biol. Volume 553. Edited by Belostotsky DA. Totowa, NJ: Humana Press; 2009:109-126 [Methods in Molecular Biology ${ }^{\mathrm{TM}}$ ].

61. Benjamini Y, Hochberg Y: Controlling the false discovery rate: a practical and powerful approach to multiple testing. J R Stat SoC 1995, 57:289-300.

62. Irizarry RA, Hobbs B, Collin F, Beazer-Barclay YD, Antonellis KJ, Scherf $U$, Speed TP: Exploration, normalization, and summaries of high density oligonucleotide array probe level data. Biostatistics 2003, 4:249-264.

63. Smyth GK: Linear models and empirical bayes methods for assessing differential expression in microarray experiments. Stat Appl Genet Mol Biol 2004, 3:Article3.

64. R Development Core Team: $R$ : A language and environment for statistical computing. Vienna, Austria: R Foundation for Statistical Computing. http://www.R-project.org/

65. Ruijter JM, Ramakers C, Hoogaars WMH, Karlen Y, Bakker O, van den Hoff MJB, Moorman a FM: Amplification efficiency: linking baseline and bias in the analysis of quantitative PCR data. Nucleic Acids Res 2009, 37:e45.

66. Bailey TL, Boden M, Buske F a, Frith M, Grant CE, Clementi L, Ren J, Li WW, Noble WS: MEME SUITE: tools for motif discovery and searching. Nucleic Acids Res 2009, 37:W202-W208.

67. Sun X, Yang Q, Xia X: An improved implementation of effective number of codons (Nc). Mol Biol Evol 2012, 30:191-196.

68. Von Arnim AG, Jia Q, Vaughn JN: Regulation of plant translation by upstream open reading frames. Plant Sci 2014, 214:1-12.

doi:10.1186/s12870-014-0306-3

Cite this article as: Gamm et al:: Increased sucrose levels mediate selective mRNA translation in Arabidopsis. BMC Plant Biology 2014 14:306.

\section{Submit your next manuscript to BioMed Central and take full advantage of:}

- Convenient online submission

- Thorough peer review

- No space constraints or color figure charges

- Immediate publication on acceptance

- Inclusion in PubMed, CAS, Scopus and Google Scholar

- Research which is freely available for redistribution

Submit your manuscript at www.biomedcentral.com/submit
C Biomed Central 